\title{
Panorama de la protección de los derechos de las trabajadoras en España y México
}

\section{Overview of the women workers' rights protection in Spain and México}

\author{
Augusto Fernando Carrillo Salgado* \\ Universidad Nacional Autónoma de México \\ ORCID ID: 0000-0001-6107-4917
}

Recibido: $04 / 03 / 2020$

Aceptado: 19/04/2020

doi: https://doi.org/10.20318/labos.2020.5773

Resumen: La finalidad de este documento consiste en describir los aspectos básicos a través de los cuales son protegidos los derechos de las trabajadoras en los sistemas normativos español y mexicano. En otras palabras, introducir al lector a la forma en que son tuteladas las prerrogativas de las trabajadoras en ambos países. El estudio de los elementos protectores de los derechos de las trabajadoras en los sistemas normativos referidos se efectúa desde tres ángulos: externo (derecho internacional), interno (derecho nacional) y judicial (actividad de sus tribunales constitucionales). Los métodos empleados en la elaboración de este documento son el deductivo, derecho comparado, histórico y analítico.

Palabras clave: Derechos de las trabajadoras, Derecho comparado, Derecho español, Derecho mexicano.

Abstract: The purpose of this document is to describe the basic elements which protect women workers' rights in the Spanish and Mexican normative systems. In other words, to introduce the reader to the way in which women workers' rights are protected in both countries. The study of the women workers' protective elements in the normative systems referred is make from three perspectives: external (international law), internal (national law) and judicial (activity of their Constitutional Courts). The methods used to elaborate this document are deductive, comparative law, historical and analytical.

Keywords: $\quad$ women workers' rights, Comparative law, Spanish law, Mexican law.

* Dedico este documento a mi padre Don Jesús Carrillo de la Cruz, licenciado en Derecho por la UNAM.

augustofernandocs@gmail.com 


\section{Introducción}

La protección jurídica de los derechos de las trabajadoras se ha convertido en un tema prioritario ya que, a pesar de los esfuerzos realizados por el gobierno espańol, no ha sido posible poner un punto final a la desigualdad que existe entre mujeres y hombres. ${ }^{1}$ En efecto, Magdalena Lorenzo Rodríguez Armas identifica el espacio de trabajo como uno de los ámbitos en donde se producen mayores discriminaciones contra las mujeres españolas. ${ }^{2}$ Por su parte, Cecilia Mondragón Herrada afirma que, en México, las mayores afectaciones contra ellas han tenido lugar en la esfera de sus derechos laborales. ${ }^{3}$ A pesar de lo anterior, deben ser reconocidos algunos progresos jurídicos acaecidos en el seno de los sistemas normativos de los países referidos.

En este documento son descritos los elementos básicos a través de los cuales se protegen los derechos de las trabajadoras en los sistemas normativos español y mexicano. Ambos sistemas fueron elegidos con base en los siguientes criterios: 1) el vínculo histórico entre ambas naciones, 2) la identidad en el lenguaje, 3) la similitud entre sus economías y 4) la exigencia social progresiva por proteger los derechos de las trabajadoras en las últimas décadas. Para la elaboración de este artículo fueron analizados diversos documentos que conforman al derecho español y mexicano. Dichos documentos fueron seleccionados a partir de las siguientes directrices: 1) pertenecer o vincularse de manera estrecha al ámbito del derecho del trabajo, 2) contener una institución protectora de los derechos de las trabajadoras y 3) exhibir alguna evolución en la protección de las prerrogativas de las empleadas de México y España.

La segunda parte de este trabajo se integra por tres subapartados a través de los cuales son descritas, grosso modo, algunas instituciones del sistema normativo español que protegen los derechos de las trabajadoras. La composición de esta sección se hace a partir del análisis de diferentes artículos del Tratado de la Unión Europea (TUE) y su Tratado de Funcionamiento (TFUE), tres directivas del Consejo de la Unión Europea, ciertos artículos de la Constitución Española (CE) y la Ley del Estatuto de los Trabajadores (LET); así como cinco sentencias del Tribunal Constitucional de Espańa (TC).

$\mathrm{Al}$ igual que en el apartado anterior, la tercera sección se compone por tres parágrafos en donde son descritas de manera general algunas instituciones jurídicas del sistema normativo mexicano que protegen los derechos de las trabajadoras a través del análisis de diferentes artículos de la Convención sobre la Eliminación de todas las Formas de Discriminación contra la Mujer (CEDAW por sus siglas en inglés) y siete observaciones finales de su comité, determinados numerales de la Convención Interamericana para Prevenir, Sancionar y Erradicar la Violencia contra la Mujer (conocida como convención Belém do Pará), diversos convenios de la Organización Internacional del Trabajo (OIT), distintos artículos de la Convención Americana sobre Derechos Humanos (mejor conocida como Pacto de San José Costa Rica), distintas disposiciones de la Constitución Política de los Estados Unidos Mexicanos (CPEUM) y su norma secundaria la Ley Federal del Trabajo (LFT); así como dos criterios jurisprudenciales sustentados por la Suprema Corte de Justicia de la Nación (SCJN).

Por último, en la cuarta parte, se exponen tres características del sistema normativo español y tres elementos del sistema normativo mexicano a fin de subrayar la forma en que se han tutelado los derechos de las trabajadoras en ambos países.

\footnotetext{
${ }^{1}$ Véase, PARDO GARCÍA, María del Carmen, "Working Time and Family Responsibilities in Spanish Labour Law: an Overview on the Current Situation”, en Spanish Labour Law and Employment Relations Journal, Vol. 5, No. 1-2-, octubre 2016, pp. 57-71.

2 Véase, RODRÍGUEZ-ARMAS, Magdalena Lorenzo, "La igualdad real y efectiva desde la perspectiva del género en la jurisprudencia del tribunal constitucional federal alemán y el tribunal constitucional español”, en Anuario Jurídico y Económico Escurialense, XL (2007), p. 192.

${ }^{3}$ Cfr, MONDRAGÓN HERRADA, Cecilia, "El avance de los derechos de las mujeres en México", en ÁLVAREZ GONZÁLEZ, Rosa María y Moreno Bonett, Margarita (coordinadoras), El Estado laico y los derechos humanos en México, México, UNAM, tomo II, 2012, pp. 197-208.
} 


\section{La protección jurídica de la trabajadora en el sistema normativo español}

Los derechos que protegen a las trabajadoras españolas emanan de tres fuentes. En primer lugar, se encuentran el TUE y su TFUE, las directivas del Consejo de la Unión Europea y las sentencias que dicta el Tribunal de Justicia de la Unión Europea; ${ }^{4}$ estos componentes son directrices de carácter externo porque no son producidas por el poder legislativo de Espańa. En segundo lugar, se encuentra la CE de 1978 (en cuya redacción influyó en forma decisiva el egregio maestro Don Gregorio Peces-Barba Martínez $)^{5}$ la cual alberga en su texto principios que permean al resto del ordenamiento español y sirven como directivas axiológicas en la producción del derecho; las disposiciones en materia del trabajo contenidas en la CE son desarrolladas por la LET. Las dos piezas anteriores constituyen el ingrediente interno del derecho español (derecho nacional). Por último, se encuentran las sentencias del TC, estas resoluciones son el elemento judicial dentro del sistema protector de los derechos de las trabajadoras en España. A continuación, son descritos someramente los elementos que constituyen estas tres perspectivas.

\subsection{Elemento externo}

El TUE consagra en sus artículos 2, 3.3. párrafo segundo y 9, el respecto a la dignidad humana, el combate de la exclusión social y discriminación, así como la igualdad entre mujeres y hombres. ${ }^{6} \mathrm{En}$ el TFUE también se encuentran disposiciones en favor de las mujeres; tal es el caso de los artículos 8 y 19, por medio de los cuales se establecen como directrices para la Unión Europea (UE) la eliminación de la discriminación por cualquier motivo y la promoción de la igualdad entre mujeres y hombres. Por su parte, el artículo 153.1, i) prescribe la obligación de promover la igualdad de oportunidades y trato en el trabajo; de acuerdo con el artículo 157, cada Estado está obligado a garantizar la aplicación del principio de igualdad de retribución entre mujeres y hombres para un mismo trabajo o para uno de igual valor. ${ }^{7}$

Las directivas del Consejo de la Unión Europea constituyen otra fuente externa para la protección de los derechos de las trabajadoras. En la directiva 76/207/CEE se establece por primera vez el principio de igualdad de trato en el trabajo entre mujeres y hombres, dicho principio consiste en la eliminación de toda discriminación por razón de sexo en el acceso, promoción y formación profesional entre mujeres y hombres. Es importante destacar que este principio posee una dimensión tanto formal como material; en otras palabras, no basta adecuar el marco normativo para asegurar la tutela de dicho principio, sino que es necesario volcar todos los esfuerzos a su consecución material. ${ }^{8}$

A través de la directiva 2000/78/CE de 27 noviembre de 2000 se introducen en forma expresa los conceptos de discriminación directa e indirecta, se precisa que la apreciación de los hechos de los que pueda resultar la presunción de haberse producido un acto u omisión de discriminación corresponde a los órganos judiciales de cada país; así mismo, se instituye la reversión de la carga de

\footnotetext{
${ }^{4}$ Véase, SÁNCHEZ TRIGUEROS, Carmen, "Concepto y fundamentación jurídica de las acciones positivas y la promoción profesional de las mujeres en la jurisprudencia del TJUE”, Femeris, Vol. 4, No. 2, 2019, pp. 50-69. La consulta de este artículo se recomienda por dos motivos. En primer lugar, por el alto rigor metodológico de la autora. En segundo término, porque el análisis, en este artículo, de algunas sentencias del TJUE no abonaría nada a la discusión ya que sería opacado por la profundidad del trabajo de SÁNCHEZ TRIGUEROS.

${ }^{5}$ Véase, PECES-BARBA MARTÍNEZ, Gregorio, "La Constitución española de 1978: balance de sus 25 años", en Revista electrónica del Departamento de Derecho de la Universidad de La Rioja, No. 2., 2004, pp. 7-15.

${ }^{6}$ Véase, Tratado de la Unión Europea

${ }^{7}$ Véase, Tratado de Funcionamiento de la Unión Europea

${ }^{8}$ Véase, Directiva 76/207/CEE
} 
la prueba para que recaiga en la parte demandada cuando estos casos se presenten ante los tribunales de un país. Esta directiva es un marco mínimo de derechos en favor de la trabajadora porque estos pueden ser ampliados de acuerdo con las necesidades del país. ${ }^{9}$

La última directiva a que se hará referencia es la 2006/54/CE; dicho documento es una consolidación de otras directivas dictadas con anterioridad (incluyendo las directivas 76/207/CEE y 2000/78/CE). Este documento amplía el espectro de las directivas analizadas porque prescribe que las medidas de protección establecidas en favor de las mujeres, deben aplicarse por igual a todas aquellas discriminaciones que tienen lugar como consecuencia del cambio de sexo de una persona. Finalmente, otra aportación sobresaliente de esta directiva consiste en reconocer de manera expresa como acto discriminatorio el trato desfavorable a una mujer con motivo de embarazo o maternidad. ${ }^{10}$

\subsection{Elemento interno}

Por su parte, la CE de 1978 en sus artículos 1.1, 9.2, 10.1, 14, 40 y 53.2, instituye como valores superiores de su ordenamiento jurídico el derecho a la libertad, igualdad, el reconocimiento de la dignidad de la persona, no discriminación, pleno empleo, formación profesional y acceso al recurso de Amparo. ${ }^{11}$ Estas disposiciones se interpretan armónicamente, se encuentran interrelacionadas y se aplican a todas las ramas del derecho, en particular a la del trabajo. Tal y como se precisó anteriormente, debido a que en años recientes la protección de los derechos humanos de las trabajadoras ha adquirido mayor relevancia, las disposiciones constitucionales referidas han cobrado un nuevo significado inclinando su vocación hacia la perspectiva de género.

La LET $^{12}$ es la norma sustantiva que prescribe los derechos y deberes de las trabajadoras, dicho ordenamiento no puede contradecir las disposiciones constitucionales referidas (y ninguna otra del texto constitucional). Las disposiciones de la LET son un marco mínimo de derechos en favor de las trabajadoras que puede ser ampliado por otros documentos como, por ejemplo, los convenios colectivos de trabajo. Cabe destacar que la protección brindada a las mujeres por la LET reproduce ${ }^{13}$ muchas de las disposiciones establecidas en el TUE, TFUE y las directivas de la UE; los artículos más significativos de la LET son el 17, 28 y $55 .{ }^{14}$ A través de aquél se desarrolla el principio de no discriminación en las relaciones laborales; en este, se establece la obligación de igualdad de remuneración por razón de sexo y en el tercero se prescribe como nulo el despido de una mujer embarazada.

Como se mencionó en líneas anteriores, doctrinariamente se han identificado cuando menos dos tipos de discriminación contra las trabajadoras, a saber: directa e indirecta. Aquella consiste en una diferenciación expresa que sitúa o perpetua a las mujeres en una posición de inferioridad; la discriminación indirecta, por su parte, entraña una diferenciación tácita resultante de la aplicación de una norma o práctica que en apariencia es neutra. ${ }^{15}$ Además del cúmulo de disposiciones (tanto internacionales como nacionales) referidas en líneas superiores, el TC ha dictado una serie de sen-

\footnotetext{
${ }^{9}$ Véase, Directiva 2000/78/CE

${ }^{10}$ Véase, Directiva 2006/54/CE

${ }^{11}$ Véase, Constitución Española

${ }^{12}$ Véase, Ley del Estatuto de los Trabajadores

${ }^{13}$ Véase, MERCADER UGUINA, Jesús, "La disolución del concepto de fuente del Derecho: deformaciones y deformidades de la función legislativa en material laboral.” en Ramos Quintana, Margarita Isabel y otra (coords.), Transformaciones del Estado social y Derecho del trabajo. Libro homenaje al profesor Manuel Álvarez de la Rosa, catedrático de Derecho del trabajo y de la Seguridad Social, con motivo de su jubilación, Granada, Comares, 2014.

${ }^{14}$ Véase, MERCADER UGUINA, Jesús R. (coord.) y otros, Comentarios al Estatuto de los Trabajadores, 4a., España, Lex Nova, 2016, pp. 261-283.

15 Véase, ZOCO ZABALA, Cristina, "Igualdad entre mujeres y hombres tras 40 años de constitución española”, en $U N E D$. Revista de Derecho Politico, No. 100, septiembre-diciembre 2017, pp. 211-256.
} 
tencias en el decurso de las últimas décadas cuya finalidad ha consistido en disminuir y erradicar este y otro tipo de discriminaciones.

\subsection{Elemento judicial}

De acuerdo con Cristina Zoco Zabala la explosión de la actividad protectora del TCE comenzó en la década de los ańos $90 .{ }^{16} \mathrm{Si}$ bien es cierto la actividad más fecunda del TC puede localizarse a partir de 1990, no debe pasar inadvertido que la tutela de los derechos de las trabajadoras comenzó 7 años atrás en la sentencia (STC) 7/1983. En ella, el TC reconoce el derecho de las trabajadoras a no ser discriminadas (a través de la aplicación del art. 107 c) de la Reglamentación Nacional de Trabajo de la CTNE publicada en noviembre de 1958) por la Compañía Telefónica Nacional de España al despedir a cinco trabajadoras por haber contraído matrimonio. ${ }^{17}$

Por otra parte, en la STC 145/1991 de $1^{\circ}$ de julio el TC reconoce el derecho de las recurrentes a no ser discriminadas en su salario por razón de sexo y anula la sentencia de la Sala Primera del Tribunal Central de Trabajo (SPTCT) de 18 de noviembre de 1988. Los hechos son los siguientes. El 27 de enero de 1989, 138 trabajadoras impugnaron una sentencia de la SPTCT que revocaba la resolución dictada por la Magistratura de Trabajo que declaraba como discriminatorio el pago de un salario inferior para las mujeres de limpieza en relación con el percibido por los Peones establecido en el Convenio Colectivo aplicable al Hospital Gregorio Marañón. El TC estimó contrario al artículo 14 de la CE el convenio colectivo referido en donde se fijaba el pago de un salario inferior ya que, a pesar de la diferente denominación de ambas categorías, materialmente las funciones eran las mismas. ${ }^{18}$

En la STC 229/1992 de 14 de diciembre el TC reconoció a Concepción Rodríguez Valencia su derecho a no ser discriminada y a ocupar la plaza de ayudante minero en Hulleras del Norte, S.A. (HUNOSA). Los hechos se desarrollaron de la manera siguiente: la recurrente cumplimenta una solicitud y supera todas las pruebas de ingreso para ocupar una de las 900 plazas ofertadas por la empresa referida; sin embargo, no le es permitido ocupar ningún puesto. En tal virtud interpone una demanda la cual es desestimada por la aquella entonces Magistratura de Trabajo, posteriormente promueve recurso de suplicación el cual sigue la suerte de la primera sentencia. En ambas resoluciones se aduce la vigencia y aplicaciones de diversos preceptos nacionales e internacionales que prohíben el trabajo de las mujeres al interior de una mina; el TC decide, empero, reconocer los derechos de la impetrante al considerar que tales disposiciones carecen de una base científico-objetiva. ${ }^{19}$

Un criterio similar al plasmado en la STC 145/1991 fue adoptado en la STC 286/1994 (empero, refinado y ampliado). En la segunda sentencia, el TC reconoció a las trabajadoras adscritas al departamento de empaquetado de la empresa Galletas Fontaneda, S.A., que esporádicamente trabajaban en el departamento de producción, el derecho a no ser discriminadas por razón de sexo en materia salarial y declaró la nulidad parcial de las sentencias dictadas por el Juzgado de lo Social de Palencia (22 de octubre de 1992) y por la Sala de lo Social del Tribunal Superior de Justicia de Castilla y León (21 de diciembre de 1992). ${ }^{20}$ En la empresa referida habían dos departamentos: producción y envasado. Aquel se encuentra compuesto fundamentalmente por hombres y este por

\footnotetext{
${ }^{16}$ ibidem, p. 223.

${ }^{17}$ Véase STC 7/1983, de 14 de febrero

${ }^{18}$ Véase STC 145/1991, de 1 de julio

${ }^{19}$ Véase STC 229/1992, de 14 de diciembre

${ }^{20}$ Véase STC 286/1994, de 28 de noviembre
} 
mujeres; el salario de la categoría de producción era superior al de envasado. El problema radicaba en que, cuando los hombres trabajan en el departamento de envasado estos percibían un salario de producción, pero no ocurría lo mismo a contrario sensu.

La empresa demandada contestó las imputaciones aduciendo que las labores de los trabajadores eran más amplias y, además, su jornada era nocturna. Empero, el TC precisa que, aun cuando no existe una discriminación formal y que la jornada nocturna es un elemento objetivo, existe una preconcepción anacrónica e infundada a través de la cual se pretende justificar el pago de un salario inferior a las mujeres que eventualmente trabajan en el departamento de producción.

En la STC 92/2008 de 21 de julio, el TC reconoce el derecho fundamental a la tutela judicial efectiva en relación con el derecho a la no discriminación por razón de sexo de María Jesús Pérez Ledo, la anulación de las sentencias del Juzgado de lo Social núm. 1 de Badajoz (24 de marzo de 2004) y la Sala de lo Social del Tribunal Superior de Justicia de Extremadura (17 de enero de 2005); así como la nulidad del despido de la impetrante por motivo de embarazo. ${ }^{21}$ La demandante de amparo fue despedida el 12 de enero de 2004 por la Asociación Provincial del Metal de Badajoz quien argumentó la imposibilidad de mantener sus servicios por el encarecimiento de la nómina e innecesariedad de su puesto. La trabajadora presenta una demanda en donde solicita la nulidad del despido por discriminatorio; de acuerdo con ella su estado de gravidez, el cual ya era perceptible durante el festejo de la empresa celebrado en diciembre de 2003, motivó el despido e, inclusive, a pesar de la innecesariedad de su puesto, este fue cubierto inmediatamente por un empleado varón tras su salida.

Tanto el Juzgado como la Sala desestiman su demanda esgrimiendo que la trabajadora no acreditó que su patrón tuviera conocimiento de su embarazo. Sin embargo, la característica decisiva de ambas resoluciones es su escueta fundamentación jurídica. El TC estima el despido nulo y discriminatorio pues la LET en su artículo 55.5 clasifica como tal el de las trabajadoras embarazadas; si bien es cierto la actora no probó la relación causa efecto entre el embarazo y el despido, las disposiciones españolas ya contemplaban ese supuesto y, al no fundamentar sus resoluciones, las sentencias de ambas instancias debían ser revocadas.

\section{La protección de los derechos de las trabajadoras en el sistema normativo mexicano.}

En la república mexicana la violencia contra la mujer persiste en todos los ámbitos; en particular en el trabajo. Sería imposible enunciar de manera casuística todos los actos de violencia que se ejercen en contra de las trabajadoras; quizá el ejemplo más significativo de esta situación sea el de las trabajadoras de las maquiladoras de Ciudad Juárez (Chihuahua, al norte del país) quienes se encuentran constreñidas a desempeñar jornadas extenuantes de trabajo en las condiciones más inhumanas que puedan imaginarse debido a que esta es la principal actividad en la entidad federativa (la cual se caracteriza por la pobreza y analfabetismo).

Antes de la reforma constitucional en materia de derechos humanos de junio de 2011, la protección jurídica de la trabajadora se limitaba a la raquítica regulación establecida en el texto de la CPEUM de 1917 y su ley secundaria, la LFT. La reforma aludida fue un cambio de paradigma para el sistema normativo mexicano por dos razones. En primer lugar, gracias a esta reforma se reconoció a la dignidad humana en el artículo $1^{\circ}$ de la CPEUM como el eje rector de todas las disposiciones normativas y actuaciones de las autoridades. En segundo lugar, el artículo 133 de la Constitución adquirió mayor relevancia pues por medio de él se determinó que la propia

${ }^{21}$ Véase STC 92/2008, de 21 de julio 
CPEUM, los tratados internacionales en materia de DDHH y las leyes federales serían las leyes supremas del derecho mexicano. Estos tres elementos son conocidos en su conjunto como bloque de constitucionalidad. ${ }^{22}$

Como puede observarse, mientras que la CE de 1978 ya reconocía la dignidad humana como la directriz de las leyes, actuaciones de las autoridades y resoluciones del TC; este cambio de paradigma ocurrió 33 años más tarde (junio de 2011) en México. Esta tardía modificación en la forma de concebir al derecho aproximó al sistema normativo mexicano al modelo español. En otras palabras, mientras que en España desde 1978 el sistema de fuentes del derecho era más amplio y complejo; en México, hasta antes de 2011, las fuentes supremas del derecho eran la Constitución y la Ley.

De esta manera, el actual sistema normativo mexicano (al igual que el sistema normativo español) protege los derechos de las trabajadoras desde tres ángulos: externo (derecho internacional), interno (derecho nacional) y judicial (actividad de la SCJN y su jurisprudencia). El primer ángulo se integra de manera esencial por la convención $C E D A W$ y las observaciones finales de su comité, la convención Belém do Pará, los convenios de la OIT y el Pacto de San José Costa Rica. El segundo ángulo se compone por algunos artículos de la CPEUM de 1917 (en especial el apartado A del artículo 123) y la LFT. ${ }^{23}$ Finalmente, la tercera perspectiva es de carácter jurisdiccional y se encuentra representada por la jurisprudencia y sentencias de la SCJN; sobre este tercer elemento es importante realizar tres acotaciones.

Primero, si bien es cierto la SCJN ha sido desde 1917 el tribunal supremo del país, su vocación en tanto tribunal constitucional no sería delineada sino hasta la reforma constitucional de diciembre de 1994 al delegar muchas de sus funciones en otros órganos del poder judicial de la federación para conocer de aquellas controversias de naturaleza constitucional a través del Juicio de Amparo (principalmente). ${ }^{24}$ En otras palabras, anteriormente la SCJN era un simple tribunal de legalidad. ${ }^{25}$ Es importante destacar que la SCJN comenzaría a actuar como auténtico tribunal constitucional 16 años más tarde (diciembre de 1994), en comparación con el TC.

Segundo, la SCJN puede funcionar en pleno (11 ministros) o en salas (penal, civil, administrativa y del trabajo). ${ }^{26}$ Tanto el pleno como las salas de la SCJN pueden formular algunos criterios conocidos como jurisprudencia. Además de la ley, la costumbre y la doctrina; la jurisprudencia es una fuente formal del derecho mexicano. ${ }^{27} \mathrm{La}$ jurisprudencia creada por la SCJN puede cumplir tres funciones: confirmar el texto de la ley, interpretarlo o colmar las lagunas del derecho nacional. ${ }^{28}$ La jurisprudencia que dicta el pleno de la SCJN obliga a todos los órganos judiciales de menor jerarquía. En efecto, constriñe a las propias salas de la SCJN, tribunales colegiados y unitarios de

${ }^{22}$ Véase, CRUZ PARCERO, Juan Antonio, Hacia una teoría constitucional de los derechos humanos, México, Instituto de Estudios Constitucionales del Estado de Querétaro, 2017, pp. 39-95. En esta obra el autor explica con detalle las causas que motivaron la reforma constitucional en materia de DDHH de junio de 2011 la cual puede traducirse como la modificación normativa más significativa para México en la última década.

${ }^{23}$ Véase, DÁVALOS MORALES, José, Derecho Individual del Trabajo, 25a ed., México, Porrúa, 2020, pp. 49-61 y 441-451.

${ }^{24}$ Véase, BARRERA GARZA, Oscar, Compendio de Amparo, 2a ed., México, Porrúa, 2017, 15-23 y 44-60 y Cfr. CHAIRES ZARAGOZA, Jorge, "La independencia del Poder Judicial", en Boletín Mexicano de Derecho Comparado, nueva serie, año XXXVII, número 110, mayo - agosto de 2004, pp. 523-545 y GÓMEZ MARINERO, Carlos Martín, "Algunas reflexiones en torno al Consejo de la Judicatura Federal en México", en Revista Legislativa de Estudios Sociales y de Opinión Pública, Volumen 4, Número 6, julio - diciembre de 2011, pp. 175-206.

${ }^{25}$ Véase, TENA RAMÍREZ, Felipe, Derecho constitucional mexicano, 40a ed., México, Porrúa, 2019, 477-480 y $491-506$ y Cfr. Burgoa Orihuela, Ignacio, Derecho constitucional mexicano, 20a ed., México, Porrúa, 2010, 882-895

${ }^{26}$ BURGOA ORIHUELA, Ignacio, El juicio de Amparo, 43a ed., México, Porrúa, 2012, p. 819 y ss.

${ }^{27}$ Véase, GARCÍA MÁYNEZ, Eduardo, Introducción al estudio del derecho, 65a ed., México, Porrúa, 2019, p. 51 y ss.

${ }^{28}$ Véase, ROJAS CABALLERO, Ariel Alberto, La jurisprudencia del poder judicial de la federación. Manual para su consulta y aplicación, 5a ed., México, Porrúa, 2017, pp. 3-4. Se recomienda la consulta de este libro porque la creación de la jurisprudencia en México es mucho más compleja de lo que se expone en este artículo. 
circuito, juzgados de distrito, tribunales militares, juzgados de las entidades federativas y tribunales del trabajo (tanto federales como locales). ${ }^{29}$

A un lado de la jurisprudencia que dictan el pleno o las salas de la SCJN se encuentran las tesis aisladas. Una tesis aislada presenta las mismas características y cumple con las mismas funciones que la jurisprudencia; sin embargo, no es un criterio vinculante. ${ }^{30}$ En otras palabras, una tesis aislada es un simple precedente. Las tesis aisladas son soluciones temporales que pueden adquirir la naturaleza de jurisprudencia mediante un proceso especial; o ser superadas por una tesis posterior. Estas nacen como respuestas temporales partiendo de las circunstancias político-sociales de una época determinada. ${ }^{31}$

Tercero, las sentencias que dicta la SCJN son diametralmente opuestas a las resoluciones del TC de España; sus características son: 1) extensión amplia, 2) utilización de un lenguaje técnico y 3) incluyen transcripciones innecesarias de jurisprudencias, tesis aisladas o artículos de alguna ley. En efecto, las sentencias de la SCJN han llegado a comprender más de 100 hojas; esta característica (además de hacer fatigosa la lectura) complica la comprensión de un problema, así como el entendimiento de la solución planteada. Por si fuera poco, la utilización de un lenguaje técnico mina la vocación democrática de la Corte pues es necesario emplear un vocabulario fácilmente comprensible por todas las personas tal y como lo hace el TC. Por último, sin duda alguna, un tribunal constitucional se legitima de manera permanente a través de los argumentos democráticos de sus resoluciones y no por transcribir criterios y leyes en sus sentencias.

Hechas las precisiones anteriores, en los siguientes tres apartados son explicados los elementos esenciales que protegen los derechos de las trabajadoras en México desde tres ángulos: externo, interno y judicial.

\subsection{Elemento externo}

México guarda una estrecha y cordial relación con la ONU; ${ }^{32}$ dicha situación puede ser explicada a partir de dos factores. En primer término, la cercanía geográfica entre la república mexicana y la sede la ONU (San Francisco, EEUU). En segundo lugar, la apertura mexicana a la política internacional (la cual se agudizó a partir de la década de 1980). En harás de salvaguardar la integridad de las mujeres, la Asamblea General de la ONU adoptó la $C E D A W$ y creo un comité especializado para vigilar el cumplimiento de las disposiciones de dicha convención en 1971.

Las disposiciones de la CEDAW han vinculado a México desde el 23 de marzo de 1981 (fecha en que el tratado fue ratificado por el Senado). Con la finalidad de incentivar la inversión extranjera en el país, el gobierno mexicano ha realizado un esfuerzo significativo (aunque insuficiente) por cumplir con lo prescrito por la CEDAW; así como las observaciones finales del comité. Es por ello que esta convención y las observaciones finales han permeado todas las ramas del derecho mexicano (en particular la del trabajo) y condicionado una gran parte de las políticas públicas del país.

Son cinco los artículos más importantes de la CEDAW. El artículo 2 establece los compromisos de los Estados signatarios, el 4 la obligación de adoptar medidas temporales para acelerar la igualdad de facto entre mujeres y hombres, el 11 prescribe la obligación de asumir todas las medidas para eliminar la discriminación contra la mujer en el empleo y el 15 obliga a los signatarios a reconocer legalmente en un plano de igualdad a las mujeres y hombres. Los artículos anteriores

\footnotetext{
${ }^{29}$ Véase, SÁNCHEZ BRINGAS, Enrique, Derecho constitucional, 11 a ed., México, Porrúa, 2007, pp.529-530.

${ }^{30}$ Véase, BURGOA ORIHUELA, Ignacio, El juicio ..., op. cit., p. 819 y ss.

${ }^{31}$ Véase, ROJAS CABALLERO, Ariel Alberto, op. cit., p. 46 y ss.

${ }^{32}$ SEARA VAZQUEZ, Modesto, Política exterior de México, $3^{\text {a }}$ ed., México, UNAM, p. 171 y ss.
} 
son de carácter sustantivo; en tanto que la naturaleza de los numerales 17 y $18^{33}$ es adjetiva porque contemplan el establecimiento de un comité de vigilancia de las disposiciones de la convención por parte de los Estados miembros, el cual se encuentra facultado para proponer medidas ad hoc las cuales son llamadas observaciones finales.

Hasta el momento se han formulado 7 observaciones a México. La primera fue la A/39/45 y se basa en el reporte inicial proporcionado por México en agosto de $1983 .{ }^{34}$ En la observación se precisa que el Estado mexicano, a pesar del incremento de trabajadoras ocurrido entre 1970 y 1979 , no contaba: con ninguna base constitucional o legal para prevenir o erradicar su discriminación, con información estadística que brindara al Comité una panorámica clara sobre su situación en México ni con alguna institución que las asistiera en el ejercicio de sus derechos. ${ }^{35}$ De acuerdo con el informe del Estado mexicano, el medio más eficaz que se tenía para proteger sus derechos era el Juicio de Amparo.

En la observación A/45/38, México comunica un avance significativo pues por primera vez ofrece datos estadísticos (1990) limitados al sector formal de trabajadoras. ${ }^{36}$ En la observación A/53/38/Rev.1, México informa que la CPEUM garantiza (formalmente) la igualdad de derechos entre mujeres y hombres en diferentes ámbitos, incluyendo el laboral. El Comité subraya que las trabajadoras mexicanas hacen frente tanto a las responsabilidades laborales como a las familiares en un contexto de salarios bajos. Además, identifica como sector vulnerable a las empleadas domésticas. Por primera vez detecta que en algunas fábricas del norte del país se piden pruebas de embarazo como requisito para obtener un puesto. Así, determina que la atención debe centrarse en la eliminación de estereotipos de género entre la población los cuales impiden un reparto equitativo de las labores del hogar, redoblar los esfuerzos en lograr una igualdad material real entre mujeres y hombres y adoptar la Convención Belém do Pará. ${ }^{37}$

En la observación A/57/38 el Comité subraya la ausencia de una compilación de criterios judiciales respecto a la protección de las trabajadoras, reitera su preocupación sobre el hecho de que la mayor parte de los empleos de las mujeres son informales y subraya que la demanda de pruebas de embarazo subsiste. ${ }^{38}$ En la observación CEDAW/C/MEX/CO/6 el Comité reconoce como aspectos positivos la adopción de la Ley General para la Igualdad entre Mujeres y Hombres, la creación del Instituto Nacional de las Mujeres; no obstante, subraya la ausencia de armonización de la legislación mexicana con la convención dada la persistencia de leyes discriminatorias y enfatiza su preocupación sobre la discriminación hacia la mujer tanto en el norte como en el sur. A pesar de los ańos transcurridos, persiste la demanda de pruebas de embarazo y sugiere el fortalecimiento del mecanismo de inspección del trabajo para erradicar esta situación. ${ }^{39}$

Por otra parte, en la observación final CEDAW/C/MEX/CO/7-8 el comité aplaude la reforma constitucional en materia de derechos humanos de junio de 2011, la adopción en 2009 de la Norma Mexicana para la Igualdad Laboral entre Hombres y Mujeres (instrumento que certifica a las organizaciones públicas y privadas que incluyan perspectiva de género en sus prácticas laborales). Empero, seńala que a pesar de los avances aún persiste la demanda de pruebas de embarazo para ocupar o mantener algún puesto de trabajo; por si fuera poco, indica que 3 de cada 10 mujeres han tenido alguna experiencia de violencia en el trabajo, incluyendo acoso y abuso sexual. Así mismo, precisa que el $56.6 \%$ de las mujeres trabajan en condiciones de informalidad y que el $99 \%$ de las

\footnotetext{
${ }^{33}$ Véase, Convención sobre la Eliminación de todas las Formas de Discriminación contra la Mujer (CEDAW).

${ }^{34}$ Véase, Observación A/39/45, pp. 12 y ss.

${ }^{35}$ Idem, pp. 12-14.

${ }^{36}$ Véase, Observación A/45/38, p. 66.

${ }^{37}$ Véase, Observación A/53/38/Rev.1, pp. 32-36.

${ }^{38}$ Véase, Observación A/57/38, pp. 205-212.

${ }^{39}$ Véase, Observación CEDAW/C/MEX/CO/6, pp. 1-8.
} 
empleadas domésticas siguen siendo mujeres. En tal virtud, recomienda la aplicación de medidas afirmativas hasta erradicar dicha situación. Pero no solo eso, sugiere el fortalecimiento de los mecanismos de inspección del trabajo y conmina al Estado mexicano a ratificar el convenio 156 de la OIT sobre los trabajadores con responsabilidades familiares; así como el 189 concerniente al trabajo decente para los empleados domésticos. ${ }^{40}$

Finalmente, la observación CEDAW/C/MEX/CO/9, reconoce los avances del Estado mexicano en su marco legal, así como la implementación de diversos programas estatales creados y desarrollados para prevenir y erradicar la discriminación contra la mujer. En materia laboral, aplaude las reformas a la LFT encaminadas a lograr la igualdad entre mujer y hombres; sin embargo, expresa la preocupación del Comité sobre la persistente brecha salarial entre ambos géneros, la distribución inequitativa de las labores domésticas, los cortos periodos de maternidad, la precaria situación de las trabajadoras domésticas (quienes ganan en promedio menos de un salario mínimo al día) y el limitado acceso para las migrantes, indígenas y mujeres afrodescendientes a empleos formales. Por ello, constrińe a las autoridades mexicanas a incrementar las posibilidades de acceso a empleos formales; reforzar el principio de pago igual con la finalidad de disminuir y erradicar la brecha salarial entre mujeres y hombres. ${ }^{41}$

El segundo elemento del ángulo externo para la protección de los derechos de las trabajadoras en México es la Convención Belem do Pará; la cual fue suscrita y ratificada por el Estado mexicano en la década de los años $90 .{ }^{42} \mathrm{El}$ tratado fue confeccionado para prevenir, sancionar y erradicar la violencia contra las mujeres en todo ámbito incluyendo, por supuesto, el laboral. Para los efectos de este documento se han seleccionado cuatro artículos de dicha convención. El artículo 4, inciso g, establece la obligación del Estado mexicano de suministrar a las mujeres un recurso sencillo y rápido ante los tribunales que las ampare contra todo tipo de acto violento.

El numeral 5 es un artículo de textura abierta porque permite interconectar la convención con otros tratados de la materia aun cuando el Estado mexicano no sea parte. El artículo 133 de la CPEUM determina que los tratados internacionales de los cuales México sea parte constituyen su bloque de constitucionalidad, en tanto que esta disposición reconoce lisa y llanamente que la mujer contará con la total protección de sus derechos consagrados en los instrumentos regionales e internacionales sobre derechos humanos. Luego entonces, de acuerdo con esta cláusula, un tratado internacional del cual México no sea parte puede ser invocado en calidad de criterio rector no vinculante. Lo anterior amplía los alcances del artículo 133 de la CPEUM en beneficio de las mujeres y trabajadoras de México.

No debe perderse de vista que este documento es de carácter regional, razón por la cual en el artículo 10 se establece la obligación a cargo del Estado mexicano de informar periódicamente a la Comisión Interamericana de Mujeres sobre las medidas adoptadas para prevenir y erradicar la violencia contra la mujer. En otras palabras, el Estado mexicano está obligado a informar respecto de los avances relacionados con la protección de las mujeres, tanto al Comité CEDAW como a la Comisión interamericana de Mujeres. Finalmente, en el artículo 11 se faculta a México para solicitar opiniones consultivas respecto de este instrumento a la comisión referida.

El tercer elemento del ángulo externo para la protección de los derechos de las trabajadoras en México son los convenios de la OIT. México se adhirió a la OIT en la década de los años 30 del siglo $\mathrm{XX}$; a través de los años ha suscrito y ratificado varios convenios entre los que destacan el 100, $111 \mathrm{y}$ 45. Los artículos más importantes del primer convenio son el 1 y $2 .{ }^{43}$ En el primer artículo se precisa que, por remuneración, debe entenderse el salario ordinario, básico o mínimo y todos sus emolumen-

\footnotetext{
${ }^{40}$ Véase, Observación CEDAW/C/MEX/CO/7-8, pp. 1-14.

${ }^{41}$ Véase, Observación CEDAW/C/MEX/CO/9, pp. 1-18.

${ }^{42}$ Véase, Convención Interamericana para Prevenir, Sancionar y Erradicar la Violencia contra la Mujer.

${ }^{43}$ Véase, C100 Convenio sobre igualdad de remuneración, 1951.
} 
tos adicionales pagables en dinero o especie. De acuerdo con este numeral, cualquier remuneración debe ser cubierta libre de discriminación basada en el sexo de la persona. Dicho en otras palabras, reafirma el principio de trabajo y salario iguales. A diferencia de algunas disposiciones aplicables en España, la palabra sexo hace referencia a una condición biológica y no una concepción cultural, razón por la cual no sería aplicable el convenio a aquellas personas que hayan estado sujetas una cirugía de reasignación sexual o se identifiquen expresamente con el género femenino. En el artículo segundo se precisan los alcances de dicho instrumento el cual permea las disposiciones internacionales, nacionales; así como los convenios colectivos y reglamentos interiores de trabajo de los Estados parte.

Los artículos más importantes del convenio 111 son el 1 y 3 . En el primero se esclarece lo que debe entenderse por discriminación; el margen protector de este convenio se extiende a la capacitación, acceso al empleo y promoción en los puestos. Empero, a diferencia de algunas disposiciones aplicables al territorio español, no determina los tipos de discriminación que pueden existir. Por su parte, el artículo tres establece como directrices la búsqueda de la cooperación entre empleados y trabajadores para erradicar toda discriminación, armonizar la legislación para tal efecto, promover programas educativos a fin de erradicar con toda práctica institucional que perpetué modelos discriminatorios. ${ }^{44}$

Por último, los numerales de mayor relevancia del convenio 45 son el 2 y 3 . En términos generales, este convenio tiene por propósito evitar la explotación física de las mujeres en las minas sin excluir su participación en dicho sector en otro tipo de puesto.$^{45}$ Este tratado debe ser abordado con precaución dado el contenido de categorías sospechosas contenidas en él y puestas de manifiesto en la STC 229/1992 de 14 de diciembre, dictada por el TC español y comentada en párrafos superiores.

El cuarto y último elemento del ángulo externo del marco protector de los derechos de las trabajadoras en México es el Pacto de San José Costa Rica. Este tratado internacional fue ratificado por el Estado mexicano el 02 de marzo de 1981; los efectos de la ratificación fueron, por una parte, la asimilación de su contenido y, por la otra, la aceptación de la competencia de la Corte Interamericana de Derechos Humanos (CIDDHH). La CIDDHH es un organismo internacional encargado de dirimir las controversias entre los Estados parte de la convención y los particulares cuando existe una lesión grave a los DDHH de las personas; como regla general, para entablar una demanda en contra del Estado mexicano es necesario agotar de manera previa todos los recursos internos.

Cabe resaltar que, hasta antes de la reforma constitucional en materia de DDHH de 2011, el contenido y la competencia de la CIDDHH eran despreciadas por el Estado mexicano. La reforma aludida y la sentencia dictada por la CIDDHH en el expediente varios 912/2010 en el Caso Rosendo Radilla Pacheco vs Estado mexicano permitieron redescubrir la importancia de la convención y la COIDDHH. ${ }^{46}$ Ambos elementos han adquirido un nuevo significado y relevancia en la protección de los derechos de las trabajadoras porque las disposiciones de la convención sirven de directrices axiológicas a todo el sistema normativo del país, en tanto que la CIDDHH salvaguarda su cumplimiento.

Los artículos más importantes del Pacto de San José son el 24, 26, 34, 41, 44 y 52. El primero de ellos prescribe la igualdad de las personas ante la ley; el segundo, instituye la obligación del desarrollo progresivo de los derechos del pacto; el tercero corresponde a las directrices de constitución y funcionamiento de la Comisión de la Corte Interamericana de DDHH; el cuarto sus funciones. El artículo 44, faculta a toda persona a presentar peticiones que contengan denuncias al pacto y, finalmente, el artículo 52 marca las pautas de constitución y funcionamiento de la CIDDHH. ${ }^{47}$

\footnotetext{
${ }^{44}$ Véase, C111 Convenio sobre la discriminación (empleo y ocupación), 1958.

${ }^{45}$ Véase, C045 Convenio sobre el trabajo subterráneo (mujeres), 1935 (núm. 45)

${ }^{46}$ Véase, GARCÍA RAMÍREZ, Sergio y MORALES SÁNCHEZ, Julieta, La reforma constitucional sobre derechos humanos (2009-2011), 3a ed., Porrúa, UNAM, México, 2013.

${ }^{47}$ Véase, Convención Americana sobre Derechos Humanos.
} 


\subsection{Elemento interno}

Por otro lado, los artículos de la CPEUM que protegen los derechos de las trabajadoras son el 1, 4, 5, 17, 94, 103 y 107, 123 apartado A y 133. El primero de ellos sitúa a la dignidad humana como el eje de las disposiciones normativas mexicanas. El 4 instituye la igualdad entre mujeres y hombres, el 5 la libertad de empleo, el 17 el acceso a un recurso efectivo, el 94 el ámbito competencial de los tribunales federales; el 103 y 107 sientan las bases del Juicio de Amparo, el 123 apartado A es la base del derecho del trabajo en México y, finalmente, el 133 precisa las normas que constituyen el bloque de constitucionalidad. ${ }^{48}$

En febrero de 2017 fue reformado el artículo 123, apartado A de la CPEUM. Esta modificación impactó en la LFT, fueron sustituidas las Juntas de Conciliación por Tribunales del Trabajo (federales como locales); se creó el Centro Federal de Conciliación y Registro Laboral que registrará todos los contratos colectivos de trabajo del país y se instituyó la conciliación como requisito previo al ejercicio de la acción. Estas novedades fueron acompañadas de una ampliación de la protección de los derechos de las trabajadoras. ${ }^{49}$ Los artículos más importantes son el 3, 86, 164-172, 331-343 y 685 Ter. Estos artículos prescriben la igualdad entre mujeres y hombres, la garantía de un ambiente libre de violencia, igualdad en el salario, la protección al embarazo y maternidad, la protección de las personas que trabajan en el hogar y la excepción de agotar el proceso conciliatorio cuando se despida a una mujer embarazada.

\subsection{Elemento judicial}

En años recientes la protección judicial de los derechos de las mujeres y, en particular de las trabajadoras, ha adquirido mayor relevancia debido a su continua transgresión (tanto por autoridades como por particulares). A pesar de lo anterior, en realidad, son pocos los criterios que han adquirido la calidad de jurisprudencia ya que, tanto el pleno como las salas de la SCJN, a pesar de la enorme presión social ejercida, se han comportado en forma tímida. En otras palabras, a diferencia de la extensa labor realizada desde la década de los años 80 del siglo XX por el TC de España, la actividad de la SCJN es reciente y limitada. En efecto, en México no existe una tradición tan amplia en cuanto a protección judicial de los derechos de las trabajadoras como sí ocurre en España. Bajo esta óptica serán analizados dos criterios de la SCJN, una jurisprudencia y una tesis aislada.

El rubro del primer criterio es Acceso a la Justicia en Condiciones de Igualdad. Elementos para Juzgar con Perspectiva de Género. ${ }^{50}$ Esta jurisprudencia dictada por la primera sala de la SCJN (sala civil, por cierto) es un método aplicable a cualquier controversia en donde se identifique una relación de desequilibrio entre las partes relacionada con un tema de género. Cabe destacar que este criterio puede ser aplicado por cualquier autoridad judicial de manera oficiosa o a petición de parte.

El método comprende seis pasos: 1) identificar si existe una situación de poder que por cuestiones de género entrañen un desequilibrio, 2) cuestionar los hechos y valorar las pruebas eliminando estereotipos, 3) ordenar la práctica de toda prueba necesaria para visibilizar tales cuestiones, 4) cuestionar la neutralidad del derecho aplicable y evaluar el impacto de la posible solución propuesta, 5) aplicar los estándares de derechos humanos y 6) evitar el uso de lenguaje basado en estereotipos o prejuicios.

\footnotetext{
${ }^{48}$ Véase, Constitución Política de los Estados Unidos Mexicanos

${ }^{49}$ Véase, Nueva Ley Federal del Trabajo, 8a ed., México, Gallardo Ediciones, 2020, 533 pp. Cfr. con MARQUET GUERRERO, Porfirio, Ley Federal del Trabajo. Comentada y correlacionada, México, Gallardo Ediciones, 2016, 524 pp.

${ }^{50}$ Cfr. Tesis: 1a./J. 22/2016, Gaceta del Semanario Judicial de la Federación, Décima Época, libro 29, abril de 2016, p. 836.
} 
¿Este criterio representa realmente un avance en la protección de los derechos de las trabajadoras? Por un lado, se impone el deber a todo órgano jurisdiccional de impartir justicia desde una perspectiva de género. Más adelante, se constriñe al juzgador a identificar situaciones de poder que por cuestiones de género puedan producir un desequilibrio entre las partes. ¿Quién se encuentra obligado a seguir la metodología de género, el órgano jurisdiccional o el juzgador?

Un órgano jurisdiccional es un concepto que comprende tribunales, juzgados y autoridades administrativas. Éste se encuentra integrado por diversas personas: en la cúspide se hayan los magistrados o jueces, debajo de ellos el personal administrativo. Es humanamente imposible que un solo ser humano (juzgador) se encuentre al tanto de todos los asuntos que se ventilan en su juzgado o tribunal; razón por la cual el titular de un órgano jurisdiccional debe contar con un equipo de trabajo que le informe de las controversias que ameriten una protección especial. Por tanto, quien debe aplicar el método referido debe ser el órgano jurisdiccional en su conjunto, ello implica la capacitación constante del personal de los órganos jurisdiccionales. Empero, ¡el Estado mexicano cuenta con los recursos humanos y materiales para realizar dicha tarea?

Por si fuera poco, el texto de la jurisprudencia que se analiza es omiso en precisar en qué momento procesal debe aplicarse el método de la perspectiva de género. ¿Debe emplearse al presentarse la demanda o es posible invocar su utilización en todo momento? ¿Precluye el derecho para solicitar la aplicación del método de la perspectiva de género? Por otra parte, ¿cuál es el límite de la subjetividad del juzgador al cuestionar los hechos? ¿Qué sucederá cuando un juzgador, de la lectura de los hechos del escrito inicial de demanda, crea advertir una situación de desequilibrio entre las partes por cuestiones de género, pero en realidad ésta no exista? ¿La práctica de diligencias sobre situaciones inexistentes no constituiría un derroche innecesario de recursos humanos y materiales que impedirían sustanciar con celeridad los procedimientos?

Si bien es cierto esta jurisprudencia representa un avance significativo en la búsqueda por proteger los derechos de las mujeres y trabajadoras; en realidad su eficacia es cuestionable. La falta de claridad en su redacción y la ausencia de capacitación del personal que integra un órgano judicial podría limitar la eficacia del criterio referido a un simple buen deseo. Dicho en otras palabras, este criterio es una reacción débil frente a la fuerte exigencia social consistente una protección efectiva de los derechos de las trabajadoras.

El segundo criterio que será analizado, lleva por rubro Ofrecimiento de Trabajo. Aun cuando se considere de buena fe, no debe tomarse en cuenta para la distribución de las cargas probatorias cuando el despido se da durante el periodo de embarazo de la trabajadora, al constituir un tema que obliga a juzgar con perspectiva de género ${ }^{51}$. De acuerdo con este criterio, en México, la reversión de la carga de la prueba en favor de la trabajadora en estado de gravidez es limitada pues solo resulta aplicable en la defensa conocida como ofrecimiento del empleo. De tal suerte que no aplica como presunción en todo despido que involucre a una mujer embarazada.

En los conflictos individuales suscitados con motivo de un aparente despido injustificado los patrones mexicanos pueden oponer como excepciones principales: 1) la negativa lisa y llana de la relación de trabajo, 2) la existencia de una relación diversa a la laboral entre las partes, 3) la renuncia escrita o verbal del actor, 4) el abandono del empleo y 5) el ofrecimiento del empleo. La primera de ellas se hace valer cuando no se configura formalmente el vínculo de trabajo entre las partes, la segunda cuando se tienen documentos a través de los cuales pueda acreditarse un vínculo diverso al laboral entre las partes (defensa muy arriesgada, por cierto), la tercera cuando se tiene una renuncia escrita o trata de acreditarse con testigos, la cuarta se configura al ausentarse el trabajador más de tres ocasiones en el mismo mes y la quinta cuando se pone a disposición del actor su empleo en las

${ }^{51}$ Cfr. Tesis: 2a./J.66/2017, Gaceta del Semanario Judicial de la Federación, Décima época, Libro 43, junio de 2017, Tomo II, p. 1159. 
mismas condiciones en las que se desempeñaba. Todas estas defensas tienen como objetivo principal revertir la carga de la prueba hacia el trabajador ya que todo despido (afirmación positiva) entraña por ley la presunción de ser cierto.

El segundo criterio referido subraya la tímida actuación de la SCJN pues limita su margen protector cuando se esgrime como defensa el ofrecimiento del empleo. En otras palabras, existe un abanico amplio de posibilidades en donde las trabajadoras que son despedidas con motivo de su estado de gravidez no son protegidas por el criterio referido el cual, además, no es obligatorio pues tan solo se trata de una tesis aislada. Si bien es cierto, todo despido entrańa la presunción de ser cierto, esta debería verse reforzada para el caso de que la parte actora fuera una mujer en estado de embarazo.

\section{A manera de conclusión}

Tanto en el derecho español como en el mexicano, la protección contemporánea de los derechos de las trabajadoras es compleja; esta comprende tres ángulos: externo (derecho internacional), interno (derecho nacional) y judicial (actividad de sus tribunales constitucionales). En ambos casos, la protección de los derechos de las trabajadoras se ha enriquecido gracias a las disposiciones jurídicas provenientes del derecho internacional; así como la actividad de sus tribunales constitucionales. En ambos sistemas normativos se observa un mayor progreso desde el plano externo y judicial que desde el ángulo interno.

En el caso de España, primero, las directivas del Consejo de Europa han tenido un impacto significativo en su legislación interna; así como en la actividad de su máximo Tribunal. Segundo, el TC ha desempeñado un papel central en la protección de los derechos de las trabajadoras desde las postrimerías de la década de los años 80 del siglo XX pues ha dictado sentencias progresistas cuyos temas esenciales son el derecho a la no discriminación, igualdad salarial y protección de las mujeres despedidas por motivo de embarazo. Tercero, si bien es cierto la CE y la LET constituyen la piedra angular del derecho del trabajo espańol, tan solo son un piso mínimo de derechos porque las prerrogativas de las trabajadoras se enriquecen con mayor abundancia desde otras vías.

En el caso de México, en primer lugar, debe reconocerse que la protección de los derechos de las trabajadoras se vio enriquecida gracias a la reforma constitucional en materia de DDHH de junio de 2011. En la actualidad no solo se tutelan sus prerrogativas a partir del texto de la CPEUM y LFT; por el contrario, las disposiciones de los tratados internacionales poseen fuerza jurídica de ley. En segundo término, antes de la reforma constitucional referida y desde los estertores de la década de los ańos 70 del siglo XX, en la República mexicana los progresos legislativos respecto a la protección de los derechos de las trabajadoras se encontraban determinados por las observaciones finales del comité CEDAW. Por último, en contraste con la actividad del TC, las actuaciones de la SCJN han sido tímidas pues tan solo existe una jurisprudencia (criterio obligatorio) y un par de tesis aisladas (directrices no vinculantes). Es decir, la protección de los derechos de las trabajadoras en sede judicial ha sido mayor en España que en Mexico.

Como ejemplo de lo anterior se haya la figura jurídica de la reversión de la carga de la prueba en favor de las trabajadoras despedidas con motivo de su estado de gravidez; la cual fue desarrollada por el TC. Mientras que esta opera en Espańa en todos los casos y a favor de cualquier mujer que es despedida debido a su estado de gravidez; esta característica no se replica en la jurisprudencia mexicana ya que resulta aplicable únicamente cuando la parte demandada esgrime como defensa el ofrecimiento de trabajo. 